\title{
Batuques por negros e brancos ${ }^{1}$
}

\author{
Batuques por negros y blancos \\ Batuques for blacks and whites
}

Elisabete de Fatima Farias Silva ${ }^{2}$

\begin{abstract}
Resumo
Produto da diáspora, os Batuques acontecem entre as comunidades de tambor que têm na ancestralidade sua episteme própria. A partir dos relatos de batuqueiros e das experiências em Batuques no interior paulista, pretendemos pensar a relação étnico-racial entre negros e brancos nos Batuques, desvelando o com-viver pelos tambores (SILVA, 2016) que se realiza nas negociações a nível do corpo, enquanto intersecção existencial, com enfoque na dimensão geográfica (COSTA, 2017; RATTS, 2004) dessa relação.
\end{abstract}

Palavras-Chave: Batuques; comunidade de tambor; diáspora; relação étnico-racial.

\section{Resumen}

Producto de la diáspora, los Batuques ocurren entre las comunidades de tambor que tienen en la ancestralidad su episteme propia. A partir de los relatos de batuqueiros y de las experiencias en Batuques en el interior de São Paulo, pretendemos pensar la relación étnico-racial entre negros y blancos en los Batuques, desvelando el comvivir por los tambores (SILVA, 2016) que se realiza en las negociaciones a nivel del cuerpo, mientras intersección existencial, con enfoque en la dimensión geográfica (COSTA, 2017, RATTS, 2004) de esa relación.

Palabras clave: Batuques; comunidad de tambor; diáspora; relación étnico-racial.

\begin{abstract}
Product of the Diaspora, the Batuques happen among the drum communities that have in their ancestry their own episteme. From the reports of batuqueiros and the experiences in Batuques in the interior of São Paulo, we intend to think about the ethnic-racial relationship between blacks and whites in the Batuques, unveiling the with-live by the drums (SILVA, 2016) that takes place in the negotiations at the level of the body, while an existential intersection, with a focus on the geographic dimension (COSTA, 2017; RATTS, 2004) of this relationship
\end{abstract}

Keywords: Batuques; drum community; diaspora; ethnic-racial relationship.

\section{Introdução}

\footnotetext{
1 Artigo apresentado no Simpósio Temático "Relações Étnico-Raciais na América Latina: debates interseccionais na Diáspora", durante o II Seminário Latino-Americano de Estudos em Cultura - SEMLACult em Foz do Iguaçu/PR, Brasil, 2018.

2 Mestre em Geografia (UNESP); Doutoranda em Geografia (Unicamp) Campinas, São Paulo, Brasil. $<$ lisafariasgeografia@gmail.com>
} 
Presente extensivamente na América Latina negra, os Batuques comportam uma ampla gama de manifestações da cultura popular, tocados por rica percussão, acompanhada de dança e canto, em performances e ritualísticas constituídas por uma rede de significados ancestrais internos à comunidade que os praticam. A coletividade dos Batuques são elemento essencial da prática cultural: vários tambores, vários batuqueiros, vários dançantes que comvivem (SILVA, 2016) para que o acelerado ritmo se mantenha nos diversos festejos afrolatino-americanos. Produto da diáspora, os Batuques acontecem entre as "comunidades de tambor", como denomina Dias (2014), as quais compartilham dessa visão de mundo que têm na ancestralidade sua episteme própria (OLIVEIRA, 2007) e estruturam-se entre o jogo, performance e ritual (SODRÉ, 2005), com a função de forjar e fortalecer a identidade (HALL, 2012) de uma comunidade.

Nesse quadro, este trabalho se propõe a discutir as relações étnico-raciais estabelecidas nos Batuques entre corpos negros e brancos que, efetivamente, são reconhecidos como membros participantes da comunidade de tambor. Guiada por uma postura fenomenológica atrelada à Geografia Humanista (MARANDOLA JR., 2016) que busca na experiência do serem-situação as bases para se pensar como as éticas e estéticas se constroem justamente pelo constante contato e presença próxima do "outro", a leitura dos corpos em sua relação espacial é uma possibilidade de se aprofundar nas negociações realizadas entre os sujeitos e seus lugares. Para tanto, problematizamos em "Geografia e relações étnico-raciais" a necessidade do debate; em "Corpos: encruzilhada existencial de culturas" adentraremos nas relações étnico-raciais, discutindo a ancestralidade e encantamento entre corpos no Batuque e, em "Rio Claro: a escala da experiência" trazemos relatos e vivências que adensam a problemática.

\section{Geografia e relações étnico-raciais}

Nascente nas experiências no Batuque de Umbigada e Congada, no estado de São Paulo, quando do mestrado em Geografia (SILVA, 2016), e Samba de Cacete, no Pará, por oportunidade do atual doutorado também em Geografia, a discussão aqui levantada dispõe à compreensão das relações étnico-raciais estabelecidas espacialmente entre batuqueiros negros e brancos - com destaque para a disputa pelo lugar, expressada na intensidade das relações entre corpos de acordo com as funções realizadas nos Batuques, estabelecendo fronteiras e limites entre os sujeitos. 
As relações étnico-raciais não são temas estranhos à Geografia. No entanto, (em)formado pelas ideias em curso no Brasil e reverberando a Geografia Moderna, a análise espacial apresenta um vínculo pouco evidenciado com a temática e tantas vezes não qualifica a variável raça nas discussões (COSTA 2017; RATTS, 2004).

Todavia, Ratts (2004) lembra de trabalhos históricos, considerados clássicos, que constituem a Geografia no campo científico, como os de Ratzel ("Antropogeografia”, original de 1882, em alemão) e de Raffestin (“A geografia do poder”, original de 1980, em francês), que abordaram, cada qual a seu modo, o vínculo raça e espaço.

Considerando ainda o período dos autores e obras citados acima, Ratts (2004) enfatiza que o desafio atual para pensar a espacialidade dos encontros/confrontos não se trata apenas de levantar a distribuição espacial étnico-racial, como já o fizeram alguns trabalhos clássicos em diversas ciências, além da geográfica. Depreende-se, então, que é preciso, pois, articular escalas espaciais e, ainda, intersecções de raça, classe e gênero (COSTA, 2017), entendendo os fenômenos e suas expressões a partir das experiências do ser-em-situação (MARANDOLA JR., 2016).

Em resposta a esse desafio, Ratts $(2004$, p. 84$)$ aponta alguns trabalhos que já foram capazes de articular tais necessidades dos estudos em cultura no espaço urbano, por exemplo, e que no esteio da descontinuidade de um repertório variado de identidades, como trabalha Stuart Hall, constitui um entroncamento de análise vital para se pensar um país multiétnico e plurirracial, com um passado escravista prenhe de desigualdades como o Brasil:

\footnotetext{
Nas grandes cidades é possível identificar territórios étnicos (ou raciais) demarcados pela música negra - samba e pagode (Pinho, 1999), reggae e soul (Silva, 1995), funk, rap (Souza \& Nunes, 1996) - que podem ser igualmente locais de lazer e de encontros/confrontos culturais. Não é apenas a predominância negra no agrupamento que define racialmente um território e sim um conjunto de códigos e símbolos compartilhados, enfim, um modo de vida. Outros territórios rurais e urbanos podem ser mapeados ou "etnogeografados", sejam negros (Bittencourt Jr., 1996, - Leite, 1991), indígenas (Arruti, 1996) ou vinculados a grupos de variadas identidades, além das três raças, pois o Brasil comporta espacialidades diversas qualificadas pelas relações étnicas e raciais (grifo nosso).
}

A par da necessidade de fortalecer o vínculo raça e espaço neste trabalho, concordamos com Costa (2017, p. 51) ao afirmar que "Não estamos trabalhando exatamente com sujeitos portadores de cultura em relação a suas interações com outros sujeitos 
portadores de "outras" culturas, mas de sujeitos cujas suas alteridades estão/são interseccionalizadas em diferentes contextos socioespaciais de interações sociais". Assim, depreende-se que as fronteiras e limites das relações étnico-raciais entre corpos são estabelecidos por diferentes negociações entre corpos circunscritos socioespacialmente - ou seja, não se trata de quaisquer corpos em quaisquer lugares, são corpos nos Batuques, ocorrido em lugares que foram constituídos historicamente pelas comunidades negras de tambor que lhes dão significado, como se verá mais em "Rio Claro/SP: a experiência do lugar”.

A evidência existencial da interculturalidade, já contida nos corpos em relação (COSTA, 2017), manifesta-se nos Batuques entre corpos negros e brancos em distintos modos e intensidades, em consonância com a situacionalidade espacial. Apresentar-se em um "lugar de brancos" e permitir que os brancos dancem ao som dos Batuques é diferente de agregar brancos aos Batuques, com especial ênfase ao toque dos tambores por brancos - dada toda a força desse ente ancestral (OLIVEIRA, 2007; SODRÉ 1988).

Portanto, uma apresentação de uma manifestação popular percussiva originária de matriz cultural negra - aqui abrangida pelo termo geral Batuques -, quando de caráter didático ou folclórico, por exemplo, pode permitir e, mesmo, incentivar que todos toquem nos tambores, dancem e cantem, dado o objetivo da atividade. Porém, o com-viver por tambores e tornar-se um tocador é outra situação que agrega/destaca outros elementos e embates.

Nas experiências do mestrado e atual doutorado, encontrou-se batuqueiros brancos incorporados à comunidade de tambor, tradicionalmente negra no Brasil. Ora em maior, ora em menor quantidade, corpos negros e brancos se relacionam em contextos específicos e é fundamental circunscrevê-los - se se trata de uma comunidade quilombola rural isolada, uma grande escola de samba no urbano, grupos de cultura popular relacionados ao catolicismo popular, releituras folclóricas ou tradições familiares. Descrever as relações entre os sujeitos e os espaços importa a uma leitura que visa ser geográfica e humanista, desvelando acordos e tensões do jogo (SODRÉ, 2005) que se produz ali, naquele lugar, entre aqueles sujeitos, concretamente, onde não existe uma verdade universal metafísica, mas uma aparência contingente de encantamento a nível do acontecimento presente - articulando escalas espaciais e temporais, sem contudo, ser determinado por elas.

As relações étnico-raciais ao serem espacializadas (RATTS, 2004), a partir do mundo vivido dos corpos em relação, ganham a força existencial da experiência (MARANDOLA JR., 2016) que compreende narrativas próprias e se associam certamente a outras escalas, todavia, ao estarem circunscritas é possível perceber cores, formas e intensidades que 
adensam as relações. A História aparece nos corpos, assim como a Geografia, contudo, determiná-los, a prioristicamente, é tornar opaca a realidade que se dá no jogo das relações do cotidiano.

Não se busca, de sobremaneira, traçar uma verdade ou uma lógica explicativa a toda e qualquer relação étnico-racial nos Batuques. Até porque esse objetivo já nasceria fadado ao fim de um absolutismo irreal e universalista, como tantas vezes o pregou a Ciência Moderna ao realizar estudos em cultura, principalmente, as cunhadas como "culturas tradicionais".

O que se pretende é destacar, a partir das experiências em Batuques no interior paulista, como as negociações a nível do corpo acontecem enquanto intersecção existencial, tendo por enfoque a dimensão geográfica (COSTA, 2017; RATTS, 2004) dessa relação.

\section{Corpos: encruzilhada existencial de culturas}

O conceito de intersecção trabalhado por Kimberle Crenshaw (1991) é criado, originalmente, no campo do Direito, para repensar o cruzamento raça, classe e gênero intragrupo, a partir de uma pesquisa realizada em uma casa de acolhida de mulheres que passaram por violência em Los Angeles. Crenshaw é professora da Universidade da Califórnia e da Columbia, nos Estados Unidos e ativista norte-americana nas áreas dos direitos civis, da teoria legal afro-americana e do feminismo. Przybysz e Silva (2017, p.576) interpreta que "a interseccionalidade é uma articulação de eixos identitários que dão base às desigualdades sociais e reforçam estruturas de poder, gerando posições relativas em determinados espaços e tempo".

A partir deste conceito de intersecção, originalmente desenvolvido pelo feminismo negro como descrito acima, alguns trabalhos com leituras culturais foram desenvolvidos. $\mathrm{Na}$ Geografia, destacam-se os trabalhos acerca da Geografia Feminista e Geografia Queer, de Joseli Silva (2014 apud PRZYBYSZ, SILVA, 2017; COSTA, 2017) que argumentam quanto as variadas facetas identitárias que estão sempre em negociação e articulação nos diferentes sujeitos sociais que se traduzem em relações espaciais situacionais. A respeito disso, Costa (2007) faz uma leitura desse conceito e da produção de Silva, entre outras autoras, e aponta para a interculturalidade, na perspectiva da Geografa humanista, enfocando, principalmente, a fenomenologia e o existencialismo, a fim de discutir as relações e os distanciamentos cotidianos de sujeitos cujos corpos já se definem como interseccionais. 
É da releitura de Costa (2007), sobretudo, que este texto se vale do conceito de intersecção - ou seja, destacando que os corpos já são interseccionais. Sem fôlego para se aprofundar nas questões de gênero nos Batuques neste momento, nos deteremos em destacar brevemente reflexões acerca de raça e classe nos Batuques - sabendo que os atributos não são apartados e separáveis, mas que os corpos são "atravessados por diferentes atributos evidenciados socialmente, como gênero, classe, raça, sexualidade, idade, lugar de residência, expressão estética etc. -, nos quais os sujeitos se tornam singulares em cada realidade socioespacial que convive (ou que apresenta dificuldade de conviver)" (COSTA, 2007, p. 50).

A cultura se movimenta no corpo, ao mesmo passo que o corpo é o movimento da cultura, defende Oliveira (2007) ao pensar como os elementos estruturantes do conceito de identidade se articulam entre si sem, necessariamente, estabelecer fronteiras rígidas. No corpo e sobre o corpo, discursos em encruzilhada dispõem modos de "ser" e "estar". Nessa encruzilhada de sentidos que atravessa o corpo, López (2015, p. 306) destacam que os discursos sobre o corpo foram cruciais para a constituição dos racismos, explorados nas relações de poder para classificar e hierarquizar diferenças: "Em contextos racializados, o corpo negro se torna um emblema étnico, transformando-se em suporte de construção de identidade".

Aqui, o conceito de encruzilhada trabalhado por Leda Maria Martins (1997, 2003), quanto ao corpo-encruzilhada congadeiro é especialmente relevante porque abarca também as relações étnico-raciais dos Batuques nas performances pesquisadas pela dramaturga acadêmica.

As reflexões de Martins (1997, 2003) foram muito inspiradoras ao se passar pelas experiências no interior paulista com o "Grupo Folclório Congada e Tambu de São Benedito rioclarense" (SILVA, 2016). Disso, repercutiu questões de como o corpo branco interfere na identidade da cultura negra constituída pelos corpos negros na prática dos Batuques. Percebendo em campo essas encruzilhadas de questões identitárias movediças, tanto em confronto de rejeição dos corpos brancos nos Batuques quanto de aceite, considera-se que é no campo das negociações, do jogo e do rito (SODRÉ, 1088) que se pode compreender essas relações étnico-raciais estabelecidas nos Batuques.

A partir das experiências com os batuqueiros de Congada e Tambu, no mestrado, surgiu o termo "com-viver pelos tambores" e foi, especialmente, nesse sentido, que percebemos que as relações étnico-raciais entre negros e brancos foram estabelecidas. É o que Oliveira (2007) atenta quanto ao reconhecimento das diferenças mas, de sobremaneira, da 
vivência em comum que possibilita estar-com. Ou seja, esses corpos negros e brancos que com-vivem nos Batuques podem partilhar de alguns aspectos comuns (classe, religião, parentesco) que são negociados em suas multiplicidades existenciais nos diferentes espaços relacionais e, por sua vez, outros aspectos (como a cor da pele, por exemplo) que são enfrentados por diferentes estratégias, num jogo de aceite, recusa, limites e fronteiras.

Nessa linha, pode-se entender o que Walsh (2017, p. 21) aborda como interculturalidade, a qual não aponta exatamente o problema da diversidade étnica, mas o da diferença colonial. Assim os corpos são vistos por uma "diferencia ontológica, política, epistémica, económica y de existencia-vida impuesta desde hace más de 500 años atrás, y fundamentado en intereses geopolíticos y geoeconómicos, en criterios de 'raza', 'género' y 'razón". Ou seja, um corpo negro e um corpo branco trazem consigo também histórias (e geografias) de outros tempos, lugares e corpos, que entram no jogo, mas não determinam a situação a priori. Todavia, não se desvia do fato que mesmo que corpos negros e brancos compartilhem no momento de um mesmo lugar de Batuques, a carnalidade também expressa outros lugares de disputa.

Negros e brancos nos Batuques não se trata de uma explicação simplista de reconhecimento ou tolerância da alteridade, nem tampouco da essencialização das identidades étnicas estanques. Dito de maneira mais específica, não se trata de justificar que negros e brancos com-vivam nos Batuques sem conflitos, de maneira a incorporar totalmente o modo de ser encarnado um do outro ou que Batuques é "coisa de negro" e este ou aquele espaço é para negro. Isso seria, erroneamente, ignorar as forças de tensão e resistências históricas que perfazem a dinamicidade do mundo vivido entre corpos e lugares. Deveras as relações entre corpos não são igualitárias, mesmo em face da raça, classe e gênero - pobres negros e pobres brancos não são vistos do mesmo modo ou compartilham dos mesmos mundos, assim como as relações entre homens e mulheres batuqueiros negros também tem várias nuances.

Por isso, nossa intenção não é lançar luz sobre os corpos brancos ou favorecer um discurso de integração simplista, mas desvelar como as negociações entre corpos negros e brancos implica na própria visão de mundo que perfaz os Batuques, de acordo com o contexto distinto vivido por cada comunidade de tambor: coletividade, ancestralidade, oralidade, engajamento. É preciso ser-com o ritual para participar dos Batuques, que é sagrado como entende Sodré (1988) a respeito do mundo das culturas de Arkhé.

Interpretamos que corpos batuqueiros brancos que participam ativamente das comunidades de tambor se encantaram pelo Batuque - e "o encanto não é, em si mesmo, nem bom nem mau [...] É uma atitude simplesmente. Uma atitude paradoxal, mágica, potente" 
(OLIVEIRA, 2007, p. 258). Para este filósofo que pensa a ancestralidade africana no Brasil, o encantamento é uma atitude de alteridade. $\mathrm{O}$ encantamento e a ancestralidade, desenvolvidos por Oliveira (2007), e a visão de mundo de Arkhé da cultura negra, do sociólogo Sodré (1988, 2005), são caminhos teóricos para se realizar uma leitura das relações étnico-raciais entre corpos negros e brancos nos Batuques. Os autores exploram no âmbito do vivido, a possibilidade de com-viver entre tempos distintos no horizonte da coletividade, pela força do mito, do rito e do corpo, assim as diferenças não são ignoradas, mas existe uma ligação mais forte compartilhada entre corpos e lugares. No âmbito de nossa experiência, percebemos que não basta um corpo branco querer e, nem tampouco, intitular-se batuqueiro por suas habilidades, é preciso ser aceito pela comunidade negra, mesmo que esse aceite seja parcial e esteja prenhe de conflitos a serem negociados no cotidiano dos Batuques populares.

Duas questões latentes quando a reflexão dos Batuques por negros e brancos passou a emergir com mais ímpeto nas reflexões das pesquisas desenvolvidas por nós na pósgraduação, desde 2016, quando das leituras teóricas e da convivência mais próxima a comunidades de tambor, é que (i) cotidianamente, vivemos esse mundo de valores e essa matriz cultural nas diversos habitus no Brasil e, (ii) constantemente, as pesquisas em cultura tendem a homogeneizar as tensões e acordos que se realizam em cada situação de prática cultural, pois desconsideram a existencialidade do fenômeno em suas intersecções, encruzilhadas e escalas socioespaciais.

Contudo, essas questões ainda não estão respondidas, inclusive este trabalho é, tão somente, um primeiro passo para a discussão étnico-racial nos Batuques - entendemos que o maior objetivo desse artigo é escancarar os conflitos vividos existencialmente no jogo das práticas culturais. Acreditamos que é com e para a experiência (MARANDOLA JR., 2016) que se pode compreender as regras do jogo (SODRÉ, 2005), como o que se tencionará entender o fenômeno em movimento, de acordo com a situacionalidade dos sujeitos.

\section{Rio claro: a escala da experiência}

Contextualizamos a manifestação dos Batuques em Rio Claro, interior de São Paulo, a partir de pesquisas que já se dedicaram ao fenômeno e, especialmente, ao Batuque de Umbigada na região (BONIFÁCIO, DIAS, 2016; BUENO, TRONCARELLI, DIAS, 2015; CASTRO, 2015; DEAN, 1977; FARIA, 2014; PEREIRA, 2008; SILVA, 2016). A segregação socioespacial deflagrada nas regiões/bairros e clubes para negros, no recente processo de 
urbanização no início do século passado na formação da cidade, é ouvida nos relatos dos batuqueiros mais antigos e perfaz as relações étnico-raciais ainda hoje vivenciadas.

Muitos dos lugares onde se aglomeravam famílias negras eram discriminados pelas autoridades locais e pela maior parte da população rioclarense, então composta por uma parcela significativa de imigrantes italianos e alemães (DEAN, 1977). Esses bairros eram considerados lugar de desocupados, de gente perigosa, o lugar dos pretos. A imprensa rioclarense denunciava esses locais como um espaço de indivíduos fora da ordem, vivendo numa situação de desajuste social, e que os negros eram portadores de uma cultura em decadência e deveriam ser vigiados e controlados. As "pessoas de cor" não podiam participar do footing na praça e de outros eventos sociais. Ainda que eles tivessem sua própria irmandade, banda, time de futebol e clubes sociais, outros espaços lhes eram proibidos, restringindo-lhes a circulação e o acesso aos diferentes espaços "públicos" da cidade: à inferioridade racial somava-se a social (CASTRO, 2015; FARIA 2014; PEREIRA, 2008).

A respeito dos Batuques, desde o fim do século XIX até mais da metade do século XXI, autorização, supervisão e repreensão eram casos de polícia. No código de Posturas de 1867 estavam proibidas, no âmbito urbano, "[...] as cantorias e danças conhecidas vulgarmente como batuques, sem pedido de licença da autoridade Polícia, sob pena de multa de $20 \$$ a cada um dos participantes, sendo dispensado o ajuntamento. Na reincidência sofrerá o dono da casa 4 dias de prisão e os demais 24 horas" (SANTOS, 2002, p.65 apud NASCIMENTO, 2005, p. 19).

Comentamos na dissertação (SILVA, 2016) como a prática de prender tambores e batuqueiros (no período, somente batuqueiros negros) forçou o silenciamento do Batuque de Umbigada em Rio Claro, a partir da década de 1950, tal como informado pela griô e militante negra rioclarenses, Divanilde de Paula. Dos relatos dos batuqueiros, depreendemos que:

\footnotetext{
É difícil acreditar que se seja contra um tambor, é difícil acreditar que se seja contra colares de contas de guias espirituais. Acredita-se, contudo, que se é contra as práticas, visíveis e invisíveis, que se utilizam de coisas e locais materializados. E mais, que se é contra os indivíduos que se fazem naquelas práticas. Portanto ter que solicitar permissão policial para fazer um samba com um tambu, prender e destruir o instrumento, dar ao lugar da manifestação outro sentido urbanístico para que se enfraqueça o Batuque é afetar diretamente os negros batuqueiros que tem na manifestação do Batuque de Umbigada a memória de seus ancestrais. Acaba-se com o que é material e o imaterial padece (SILVA, 2016, p. 70-71).
}

Sobre isso, Leite (2011) reflete como o registro fotográfico de um profissional infiltrado nos Batuques a mando policial revela a pressão social sofrida pelos Batuques e batuqueiros negros pelas elites locais brancas contrárias a esta prática. O filho do fotógrafo, 
em entrevista à Leite (2011, p. 148), detalha que "[...] seu pai havia recebido instruções para registrar detalhes da dança, em especial o lado visto pela elite local como promíscuo, vulgar, leviano, no qual as mulheres e os homens roçavam seus corpos, se ofereciam".

No desenrolar da História, acerca da presença de corpos brancos interessados em comviver pelos tambores, Tinhorão (2012, p. 104), em “Os sons dos negros no Brasil”, expõe um relevante processo decorrente da nova divisão do trabalho estabelecida pela produção urbanoindustrial, no qual as diferenças culturais se ampliaram e se diversificaram nas cidades: "os brancos das camadas média e alta passaram a conta com formas próprias de lazer (bailes, festas de clubes, teatros, espetáculos musicados, discos, fitas e vídeos)”, enquanto os negros, mestiços e brancos das classes mais baixas "continuaram herdeiros dos batuques, cultivando até hoje a batucada, o bate-baú, o lundu, o coco, o caxambu, o jongo, o tambor de crioula e todas as modalidades surgidas no calor dos sambas [...]". Nesse contexto de formação das cidades brasileiras, as periferias urbanas foram (e são) o lugar de contato e socialização entre pobres brancos e negros.

Contudo, é preciso relevar de que maneiras os corpos estão (em)formados pelas lógicas segregacionistas de para negros e para brancos, mesmo pertencentes a mesma condição econômica e realidade residencial. As subjetividades não se restringem de maneira geral e exclusiva às estruturas culturais em que os sujeitos nasceram situados e, ainda assim, mesmo que os corpos brancos se aproximem de corpos negros, nunca saberão/sentirão como é ser negro.

Percebemos nos Batuques que o envolvimento dos sujeitos negros/brancos se põe de acordo com o comprometimento e vivência entre os mesmos, capazes de se assumirem mutuamente em comunidade, em lugar comum - não sem conflitos e negociações. Não é, simplesmente, indo em apresentações ou sendo um "branco pobre que toca bem" que a relação étnico-racial está estabelecida, há uma gama de relações verticais e horizontais (GARCÉS, 2009). É preciso estar junto, viver-com (SILVA, 2016) para ser agregado à comunidade de tambor e, então, viver a "intimidade cultural" (COSTA, 2017) protegida pelos sujeitos frente à lógica externa de padrões éticos e estéticos.

Em Rio Claro, Celso Augusto, um dos fundadores de um dos clubes sociais negros da cidade, afirmou em um dos eventos organizados pelo Arquivo Público e Histórico do município de Rio Claro que: "não desprezo porque é branco ou porque é preto, não. A comunidade é uma comunidade, começamos como uma sociedade negra, mas nem por isso nós desprezamos os outros [...]" no contexto da participação de pessoas brancas a frente desses espaços. Ele ainda recorda "nós temos nossa congada, nós temos nossa umbigada, nós 
temos bastante coisa e nós temos o que levantar ainda, então vamos trabalhar em cima disso" (SILVA, 2016, p. 59). A ideia de coletividade ativa, da prática em ação por sujeitos que se reconhecem por uma mesma causa está bem presente na fala deste batuqueiro. Ainda assim, é relevante destacar que "começamos com uma sociedade negra": o início e a origem nunca são esquecidos, isso é parte da ancestralidade - força vital na cultura negra.

Então se, atualmente, o encantamento no com-viver pelos tambores vai além do corpo negro é porque ele é desde o corpo negro - graças ao mestre negro que ensinou a tocar o tambor, a fazer o tambor, graças à ancestralidade negra é que hoje alguns brancos se achegam no Batuque com a sensação de que isso lhes é familiar (SILVA, 2016). E é via ancestralidade que podemos compreender essas aproximações e distanciamentos entre corpos e os desdobramentos dos Batuques, por seus encontros e diferenças.

Para tanto, a filosofia da ancestralidade "ambiciona conviver com os paradoxos, mais que resolvê-los", sendo "fruto do agora, a ancestralidade ressignifica o tempo do ontem [...] é uma forma cultural em si mesma ética porque o contorno de seu desenho é uma circularidade que não admite o excluído" (OLIVEIRA, 2007, p.37).

Disso, compreendemos como a relação étnico-racial entre corpos batuqueiros negros e brancos se dá pela ideia de família estendida de comunidade. Sem, contudo, diminuir o peso do colonialismo branco e, também, sem delimitar e restringir o corpo à pele.

Nesse bojo, trazemos a fala de um batuqueiros negro e de uma situação recentemente vivida para adensar a reflexão: i) Ailton Oliveira, o Mestre Malvino, é um reconhecido batuqueiro rioclarense e relatou que nos Batuques de Umbigada até a década de 1950, quando o pai dele "tirava" a grande festa do 13 de maio, em Rio Claro, "tinha gente branca que ia, não entrava pra dançar, mas ficavam ali assistindo". ii) Em junho de 2018, presenciamos mais uma vez o tradicional Batuque de Umbigada, no sítio da família Soledade, em Piracicaba. Foi permitido, pelos organizadores desse evento que são da comunidade negra, que um ônibus de alunas da graduação em Dança, da Unicamp, participasse dos Batuques. As estudantes, sentadas, assistiam à performance da umbigada e depois tentaram reproduzir quando lhes foi aberto espaço para adentrar no chão de terra batido - desta situação podemos interpretar em consonância com a situação detalhada acima que as pessoas brancas assistiam a comunidade de tambor em sua prática cultural, não participavam dela, tal como relatou o batuqueiro Ailton no contexto de Rio Claro, há décadas atrás. Destacamos que a relação étnico-racial fora estabelecida em ambas situações a partir da permissão dada pelos corpos negros aos corpos brancos, delimitando os lugares. 
Permissão e reconhecimento fazem parte do jogo entre corpos e lugares. $\mathrm{O}$ fato descrito acima de situações distintas e semelhantes nos remete à referência que Sodré (1988) faz ao jogo, enquanto lugar de trânsito e de identidade, central nas culturas de Arkhé. O sociólogo denomina jogo as linguagens não conceituais dos gestos, das imagens, dos movimentos corporais e dos cantos, constituindo espaços de reterritorialização pelo corpo negro. Assim, compreendemos que as relações étnico-raciais entre corpos negros e brancos no Batuque são marcadas pelo jogo, em encruzilhadas existenciais significadas diferentemente pelos "de dentro" e "de fora" e pelas funções sociais que realizam (assistir/dançar/tocar/produzir tambores), em constante conflitos e negociações entre corpos e lugares.

\section{Conclusões}

Ainda existem muitas possibilidades de diálogo e leituras compreensivas das relações étnico-raciais entre corpos negros e brancos nos Batuques a se fazer. Aqui foi uma primeira aproximação que buscou delinear alguns contornos dessa situação, a partir de inquietações surgidas pelas experiências em Batuques no interior paulista com os quais se conviveu durante o mestrado e atual doutorado. Reiteramos que é urgente uma Geografia (e isso também é valido para as demais Ciências Humanas) que se abra às múltiplas existências e modos de "ser" e "estar" no espaço, buscando compreender os processos e modos múltiplos de negociação da existência em sua dimensão espacial. Tal como é necessário pensar os estudos em cultura assumindo os conflitos, as negociações, o jogo e as encruzilhadas vividas pelos corpos em intersecção existencial.

Pesquisar os limites e fronteiras que se delineiam nos fenômenos culturais e se expressam na espacialidade dos encontros/confrontos, sem delimitá-los exclusivamente a determinismos históricos, explicações causais ou finalistas é um desafio à Ciência que tantas vezes delimita a cultura, diminuindo sua vitalidade, sem se aperceber do jogo sutil e negaciado dos Batuques que permite a uns e não a outros o com-viver pelos tambores, de acordo com a intensidade das relações estabelecidas que não escondem as diferenças dos vários atributos existenciais. Porém que, a todos e a qualquer um, dispõe seu mundo de valores, nas rodas e cortejos dos diversos Batuques Brasil a fora. 


\section{Referências}

BONIFÁCIO, I.S.; DIAS, P. Terreiros do Tambu: histórias sobre os tambores no batuque de umbigada. Rio Claro: Associação Cruzeiro do Sul, 2016.

BUENO, A.P.; TRONCARELlI, M.C.; DIAS, P. (org.). Batuque de Umbigada: Tietê, Piracicaba, Capivari-SP. São Paulo: Associação Cultural Cachuera! 2015.

CASTRO, B.A.C. de. Patrimônio cultural e territorialidade negra em Rio Claro/SP. Espaço \& Geografia (online), v. 16, n. 2, p. 557 - 578, 2013. Disponível em: <http://www.lsie.unb.br/espaco egeografia/index.php/espacoegeografia/article/view/269>. Acesso em: 24 nov. 2016.

COSTA, B. P. da. Interculturalidade e geografia: um debate espacial das relações culturais. GEOgraphia, Niterói, Universidade Federal Fluminense (UFF), v.19, n.39, 2017. p. 41 - 53. Disponível em: <www.geographia.uff.br/index.php/geographia/article/view/993>. Acesso em: 4 jan. 2017.

CRENSHAW, K. W. A intersecionalidade na discriminação de raça e gênero. In: VV.AA. Cruzamento: raça e gênero. Unifem. p. 7 - 16, 2004. Disponível em: <http://www.acaoeducativa.org. br/fdh/wp-content/uploads/2012/09/Kimberle-Crenshaw.pdf>. Acesso em: 24 nov. 2017.

DEAN, W. Rio Claro: um sistema brasileiro de grande lavoura 1820-1920. POTINHO, W.M. (trad.). Rio de Janeiro, Paz e Terra: 1977.

FARIA, M.M. de. Valorização dos percursos negros no Brasil: perspectivas de educação nos territórios afro-rioclarenses. 2014. Dissertação de Mestrado (Pós-graduação em Educação) - Instituto de Educação, Universidade Estadual Paulista "Júlio de Mesquita Filho", Rio Claro/SP, 2014.

GARCÉS, 2009. De la interculturalidad como armónica relación de diversos a una interculturalidad politizada. MORA, D. (org.) Interculturalidad crítica y descolonización: fundamentos para el debate. Bolívia: Instituto Internacional de Integración, 2009. p. 21 - 50.

HALL, S. Quem precisa da identidade? In: SILVA, T.T (Org.) Identidade e diferença: a perspectiva dos estudos culturais, 12. ed. Petrópolis, RJ: Vozes, 2012. p. 103 - 133.

LEITE, M. E. Fotografia e documentação no interior paulista: o 'batuque de umbigada' por Rodolpho Copriva. Discursos Fotográficos. Londrina, v.7, n.11, p. 175 - 195, 2011. Disponível em: < http://www.uel.br/revistas/uel/index.php/discursosfotograficos/article/view/9411 >. Acesso em: 2 nov. 2016.

LÓPES, L. C. O corpo colonial e as políticas e poéticas da diáspora para compreender as mobilizações afro-latino-americanas. Horiz. antropol. v.21, n.43, Porto Alegre, p. 301 - 330, 2015. Disponível em: <http://www.scielo.br/pdf/ha/v21n43/0104-7183-ha-21-43-0301.pdf〉. Acesso em: 14 mar 2018.

OLIVEIRA, E. D. Filosofia da ancestralidade: corpo de mito na filosofia da educação brasileira. Curitiba: Editora Gráfica Popular, 2007.

PEREIRA, F.A. de S. Organizações e espaços da raça do Oeste Paulista: movimento negro e poder local em Rio Claro (dos anos 1930 aos anos 1960). 2008. Tese (doutorado em Sociologia). UFSCAR. São Carlos/SP.

PORTAL MEMÓRIA VIVA. No Tamoyo. 8a Conversa Griô. Entrevistas. 1h48'. 06 nov. 2012. Disponível em: <http://www.memoriaviva.sp.gov.br/2014/01/06/8a-conversa-grio/>. Acesso em: 20 ago. 2015.

PRZYBYSZ, J.; SILVA, J. M. Espacialidades e interseccionalidades na vivência de mulheres prostitutas mães na cidade de Ponta Grossa-PR. Geousp - Espaço e Tempo (Online), v. 21, n. 2, p. 570-585, 2017. Disponível em: <http://www.revistas.usp.br/geousp/ article/view/117719>. Acesso em 22 maio 2018.

RATTS, A.J. As etnias e os outros: as espacialidades dos encontros/confrontos. Espaço e Cultura, UERJ, Rio de Janeiro, n.17, p. 77 - 89, 2004. Disponível em: <https://www.e-publicacoes.uerj. br/index.php/espacoecultura/article/view/7855>. Acesso em: 25 out. 2017. 
MARANDOLA JR., E. Geografias do porvir: a fenomenologia com abertura para o fazer geográfico. In: SPOSITO, E.S.; et al. (Org.). A diversidade da geografia brasileira: escalas e dimensões da análise e da ação. Rio de Janeiro: Consequência, 2016. p. 451 - 466.

MARTINS, L. M. Afrografias da memória: o reinado do rosário do jatobá. São Paulo: Perspectiva, 1997.

MARTINS, L. M. Performances do tempo e da memória: os congados. In: O Percevejo - Revista de Teatro, Crítica e Estética, Rio de Janeiro, ano 11, n. 12, p. 68 - 83, 2003. Disponível em: <www2.eca.usp.br/bctb/obra.php?cod=17084Acesso em: 25 out. 2017.

NASCIMENTO, Â.S. Os espaços negros na cidade de Rio Claro/SP. 2005. Trabalho de Conclusão de Curso (Graduação em Geografia) - Instituto de Geociências e Ciências Exatas, Universidade Estadual Paulista "Júlio de Mesquita Filho", Rio Claro/SP, 2005.

SILVA, E.F.F. Entre corpos e lugares: experiências com a Congada e o Tambu em Rio Claro/SP. Mestrado (Dissertação em Geografia). IGCE, UNESP, campus de Rio Claro, 2016.

SODRÉ, M. A verdade seduzida. 3.ed. Rio de Janeiro: DP\&A, 2005.

SODRÉ, M. O Terreiro e a Cidade. Petrópolis/RJ: Ed. Vozes, 1988.

TINHORÃO, J.R. Os sons dos negros no Brasil. São Paulo: Editora 34, 2012.

WALSH, C. Interculturalidade e (des)colonialidade? Gritos, rachaduras e semeaduras de Abya-Yala. 2017. GARCIA DINIZ, A., et. al (orgs.) Poética e política da linguagem em vias de descoloniazação. São Carlos/SP: Pedro \& João Editores: 2017. p. 19 - 53. 